\title{
Structural health monitoring of engineered structures using a space- borne synthetic aperture radar multi-temporal approach: from cultural heritage sites to war zones.
}

\author{
Pietro Milillo ${ }^{1}$, Deodato Tapete ${ }^{2}$, Francesca Cigna $^{2}$, Daniele Perissin ${ }^{3}$, Jacqueline Salzer ${ }^{4}$, Paul \\ Lundgren $^{1}$, Eric Fielding ${ }^{1}$, Roland Burgmann ${ }^{5}$, Filippo Biondi ${ }^{6}$, Giovanni Milillo ${ }^{7}$ and Carmine \\ Serio $^{8}$
}

${ }^{1}$ NASA Jet Propulsion Laboratory, California Institute of Technology, 4800 Oak Grove Drive, 91109 Pasadena (CA), USA.

${ }^{2}$ British Geological Survey (BGS), Natural Environment Research Council (NERC), Nicker Hill, NG12 5GG Keyworth, United Kingdom

${ }^{3}$ Lyles School of Civil Engineering, Purdue University, 550 Stadium Mall Drive, 47907 West Lafayette (IN), USA

${ }^{4}$ GFZ German Research Centre for Geosciences, Physics of Earthquakes and Volcanoes, Telegrafenberg, 14473 Potsdam, Germany.

${ }^{5}$ Dept. of Earth and Planetary Science, University of California, Berkeley, 389 McCone Hall, 94720 , Berkeley (CA), USA

${ }^{6}$ Italian Ministry of Defense.

${ }^{7}$ Italian Space Agency, Contrada Terlecchia, 75100 Matera (MT), Italy

${ }^{8}$ I School of Engineering, University of Basilicata, Viale dell'Ateno Lucano 10, 85100 Potenza.

\begin{abstract}
Structural health monitoring (SHM) of engineered structures consists of an automated or semi-automated survey system that seeks to assess the structural condition of an anthropogenic structure. The aim of an SHM system is to provide insights into possible induced damage or any inherent signals of deformation affecting the structure in terms of detection, localization, assessment, and prediction. During the last decade there has been a growing interest in using several remote sensing techniques, such as synthetic aperture radar (SAR), for SHM. Constellations of SAR satellites with short repeat time acquisitions permit detailed surveys temporal resolution and millimetric sensitivity to deformation that are at the scales relevant to monitoring large structures. The all-weather multi-temporal characteristics of SAR make its products suitable for SHM systems, especially in areas where in situ measurements are not feasible or not costeffective. To illustrate this capability, we present results from COSMO-SkyMed (CSK) and TerraSAR-X SAR observations applied to the remote sensing of engineered structures. We show how by using multiple-geometry SARbased products which exploit both phase and amplitude of the SAR signal we can address the main objectives of an SHM system including detection and localization. We highlight that, when external data such as rain or temperature records are available or simple elastic models can be assumed, the SAR-based SHM capability can also provide an
\end{abstract}

SAR Image Analysis, Modeling, and Techniques XVI, edited by Claudia Notarnicola, Simonetta Paloscia, Nazzareno Pierdicca, Edward Mitchard, Proc. of SPIE Vol. 10003, 100030N · @ 2016 SPIE

CCC code: $0277-786 X / 16 / \$ 18 \cdot$ doi: $10.1117 / 12.2241620$ 
interpretation in terms of assessment and prediction. We highlight examples of the potential for such imaging capabilities to enable advances in SHM from space, focusing on dams and cultural heritage areas.

Keywords: Structural health monitoring, SAR, time-series analysis, dam, archeology, COSMO-SkyMed, TerraSAR-X?

\section{INTRODUCTION}

Developing a strategy for identifying and quantifying engineered infrastructure damage is usually referred to as a structural health monitoring (SHM) system where damage is intended as a change that affects the current or future system performance. The statistical pattern recognition paradigm [1] provides a comprehensive definition of an SHM process in terms of operational evaluation, data acquisition, feature selection, information condensation and statistical model development. During the last decade SHM is one of the applications that most benefitted from remote sensing technologies [2-26-30]. Data acquisition in particular took advantage of the surge of data coming from aerial photography and optical satellite imagery and it is now beginning to adopt the second generation of synthetic aperture radar (SAR) technologies to boost operational evaluation, in complex systems such as cities [2], and statistical model development capabilities, e.g. in monitoring concrete structures [3]. Since the launch of ERS-1 in 1991 SAR gained more importance as a tool for studying natural and anthropogenic phenomena [4], but only the second generation of SAR sensors designed as constellations of satellites enabled a near real time response capability $[5,6]$. Several examples have been recently published with regard to earthquakes, volcanoes, landslides, glaciers, and natural hazards, fully exploiting the short-repeat acquisition time of SAR constellations [7-12]. The all-weather multi-temporal characteristics of SAR make SAR-derived products suitable for SHM systems especially in areas where in situ measurements are not feasible or not cost-effective. To illustrate this capability, we present results from COSMO-SkyMed (CSK) and TerraSAR-X (TSX) observations applied to the remote sensing of engineered structures. We show how by using only multiple-geometry SAR based products which exploit both phase and amplitude of the SAR signal we can address the main objectives of an SHM system, including detection and localization. A particular focus is dedicated to the engineering of dams where a detailed risk assessment is needed to avoid water impoundments, embankment breaks or overtopping and to mitigate the effects of earthquakes, landslides, hydrodynamic instability, erosion, and long-term deterioration of built structures. We show examples of different dams affected by several mechanisms of deformation, including thermal, hydrological and aging induced deformation. We also provide examples relying on CSK observations that highlight the potential advances in archaeological and cultural heritage site monitoring.

\section{METHODS}

We adopt well-established multi-temporal InSAR (MT-InSAR) techniques using time-series analysis of ground deformation extended to non-linear motion with no a priori information [13,14]. We carried out multiple sensor and parallel track analyses $[15,16]$ to collect a sufficient number of images providing temporal continuity and thereby increasing the sensitivity to thermally and hydrologically induced deformation. We merged coherently (whenever the local incidence angle varies less than 0.1 degrees between two adjacent tracks) and incoherently (during the geocoding step) two datasets performing a very precise coregistration which is the main task for data combination from multiple tracks and different sensors together with the identification of multi-angle targets. In our case light poles and a fence are located near the dams. These targets ensure sufficient amplitude stability and they are chosen as ground control points to assist the geocoding process.

In the case of archaeological and cultural heritage sites we use ascending and descending datasets to interpret deformation trends. RGB maps were generated by analyzing the SAR amplitude and used for visual inspection of the heritage assets.

\section{STRUCTURAL HEALTH MONITORING OF DAMS}

Dams are anthropogenic barriers designed to modify the magnitude and timing of the downstream water movement. In addition to the enormous advantages in terms of water, flood protection and/or electricity production, dams can pose a 
risk to the surrounding area as a consequence of a possible structural failure. A detailed risk assessment is needed to avoid water impoundments, embankment breaks or overtopping and to mitigate the effects of earthquakes, landslides, hydrodynamic instability, erosion, and long-term deterioration of built structures. Advancing the knowledge of dam engineering, construction, planning, maintenance, and performance is considered of primary importance to reduce the socio-economic risk related to dams. In particular, ageing of dams and deterioration of their foundation are among the main concerns to engineers involved in their design, construction and maintenance. The combination of InSAR and deterministic models for seasonally and hydrologically induced dam deformation allows interpreting deformation at the dam wall in near-real-time without the need of ground surveys [3]. The nature of these statistical models requires a copious number of acquisitions in order to stabilize the inverted parameters as required for interpretative models with pendulum or GPS measurements. The major limit of this kind of InSAR analysis is the relative non-orthogonal orientation of the dam walls to the satellite flight direction.

In the following paragraphs we show two examples related to the Pertusillo dam, Italy, and the Mosul dam, Iraq. In the first case study, seasonal induced deformation can be monitored and integrated with hydrological-season-time (HST) and hydrological-temperature-time (HTT) models for interpreting displacements at the dam. Conversely, in Mosul the ongoing deformation/destabilization of the dam is linked to processes of dissolution of the local evaporites underlying the dam foundation. A dam failure would threat over 1.5 million inhabitants living in Mosul and the surroundings areas.

\subsection{The Pertusillo dam, Italy}

The Pertusillo dam is a $98 \mathrm{~m}$ high and $357 \mathrm{~m}$ long arch-gravity dam impounding water coming from the Agri river collected in the "Lago di Pietra del Pertusillo", an artificial lake built between 1957 and 1962 in southern Italy (Fig 1a,c). The basin capacity amounts to $155 \times 10^{6} \mathrm{~m}^{3}$ and is mainly used for producing hydroelectric energy and irrigation of the Puglia and Basilicata regions. Given the relative LOS visibility of the Pertusillo dam [3] it is possible to monitor the thermal load and hydrostatic load due to the reservoir water variations. The thermal effect on the structural behavior of the dam is produced by solar radiation, air, and reservoir temperatures while the hydrostatic load depends on the relative water level at the dam wall. Statistical models are used to predict the structural response and are usually known as quantitative interpretative models [3]. SAR data acquired from both ascending and descending geometries can be used to discriminate horizontal vs. vertical motions and drive parametric approaches to model the thermal and hydrostatic effects. By analyzing CSK and TSX ascending and descending datasets we generated a time-series of horizontal displacements perpendicular to the dam wall and applied the HTT and HST models highlighting the global response of the dam (Fig 1c,g) and showing how InSAR-based methods can be used in combination with ground surveys at the dam and to optimize the locations of the dam monitoring stations. The high resolution of SAR stripmap images also allows estimation of deformation at a larger number of points (dozens of PS against 1 or 2 GPS and pundulums) compared to traditional techniques (GPS or pendulum measurements). The combination of InSAR and deterministic models for seasonally and hydrologically induced dam deformation allows interpretation of deformation at the dam wall in nearreal-time without the need of ground surveys [3]. 
15.5

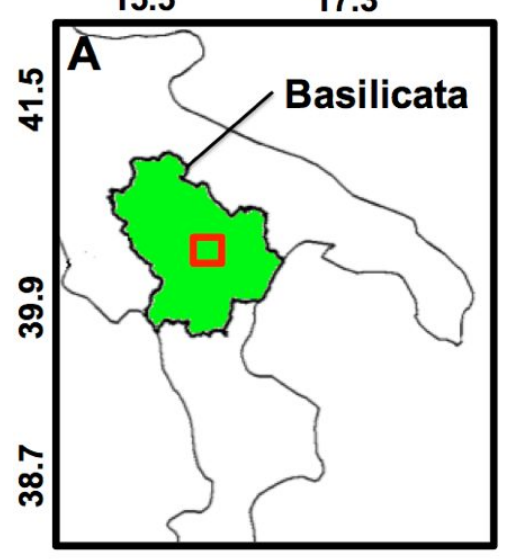

15.8

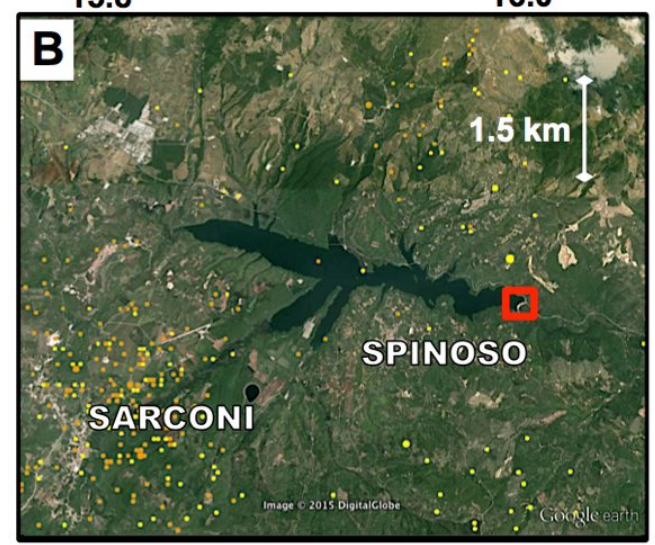

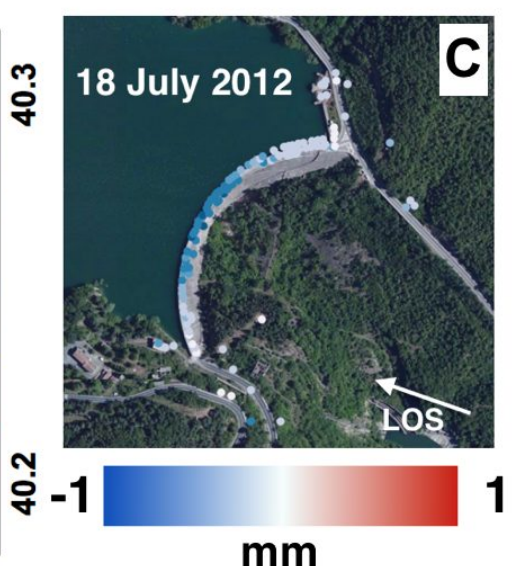

$\mathrm{mm}$
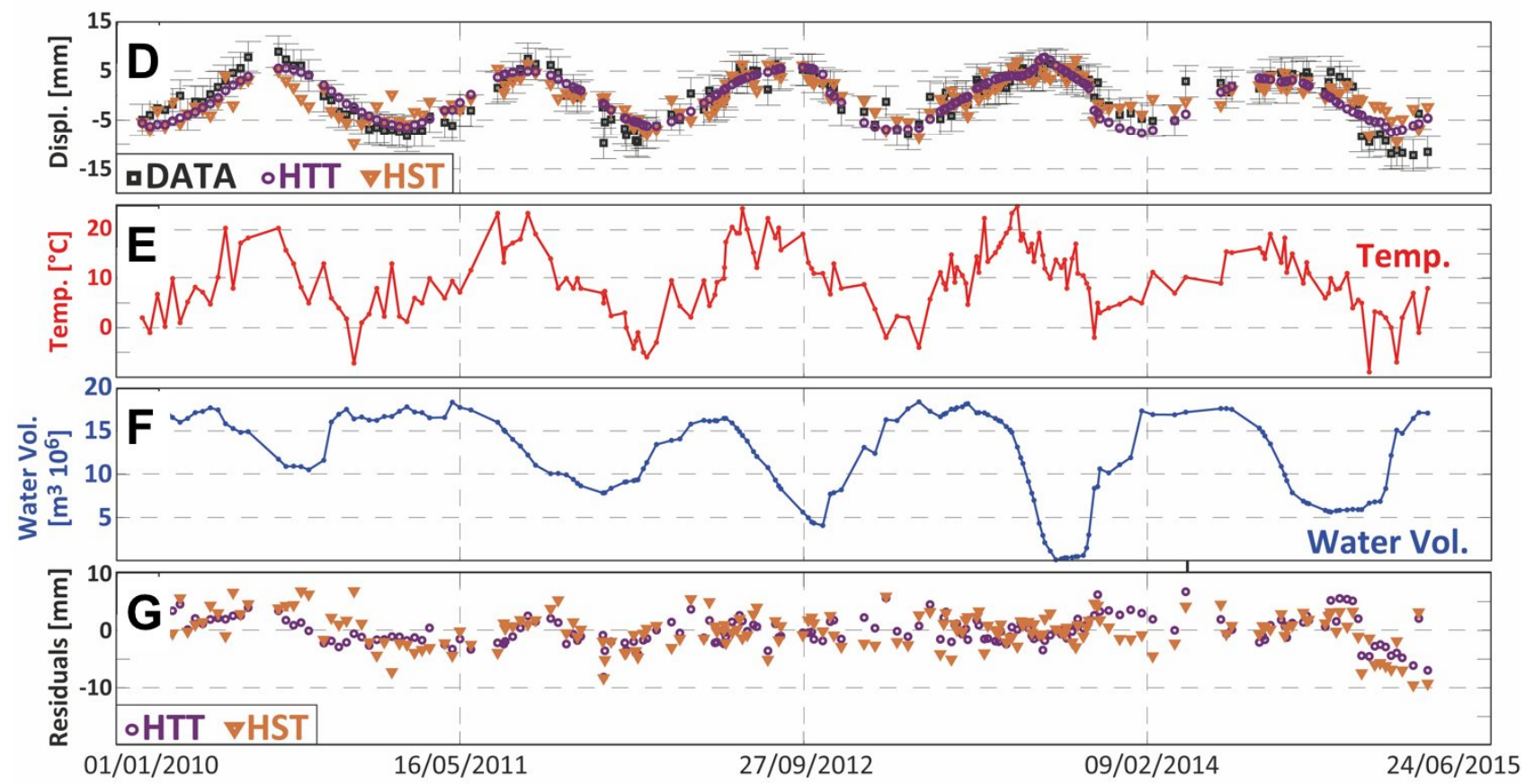

Figure 1 Overview of the study site (A) South Italian Peninsula; the red outline shows the location of the Pertusillo artificial lake in B. (B) GoogleEarth Optical Image showing the "Lago di Pietra del Pertusillo". Seismicity at the Pertusillo dam recorded by the ISIDE-INGV network. Yellow (orange) dots indicate earthquakes with 0-10 (10-20) km depth. The red box shows the extent of the dam in C. (C) Cumulative displacement maps at the Pertusillo dam as observed from different SAR sensors and different look geometries. Negative values indicates motion away from the satellite. Optical image from Bing Maps. (D) Projected horizontal displacement perpendicular to the dam recorded at the center of the dam. Legend: black squares: data; magenta triangles: HTT model; green circles: HST model. (E) Temperature records and (F) water height variation at the dam wall. (G) Residuals; Legend: magenta triangles: HTT mode; green circles: HST model. Figure modified from [3].

\subsection{The Mosul dam, Iraq}

The Mosul dam (Lat. $36.630^{\circ} \mathrm{N}$, Lon. $42.823^{\circ} \mathrm{E}$ ) is located on the Tigris river in the north of Iraq and is the biggest hydraulic structure in Iraq. It was built in 1984 as a multipurpose dam, including water supply, irrigation flood control, and power generation. The dam is an earth-fill dam $113 \mathrm{~m}$ tall, $3.4 \mathrm{~km}$ long, $10 \mathrm{~m}$ wide at its crest and has a storage capacity of 11.1 billion cubic meters. The geologic composition beneath its foundation is characterized by soluble soils (evaporates). The continuously dissolving bedrock results in the formation of cavities and voids beneath the dam structure and this requires a regular grouting program to mitigate the risk of dam failure. Because of these pre-existing geological constraints, grouting has been repeatedly implemented since the 1980s. Starting in 2005 a sinkhole appeared 
very close to the dam and raised concerns about the possibility of subsurface failure of the foundation. A United States (US) military report [17] indicates that the dam was constructed on a very poor foundation that should have had an inverted dam foundation identifying ongoing water seepage coming from the access gallery and the right and left sides of the spillway. Since 2007, a reconstruction project was initiated by the US government and operated by the US Army Corps of engineers to establish a more effective grouting system. The project obtained modest results toward maintaining the structural health of the dam [17]. In 2014, following the conflict in the area, regular maintenance and grouting stopped. An Italian company is now in charge of reestablishing the grouting. This hiatus in grouting has led to an opportunity to examine the response of the structure to potential changes in the stability of the dam's foundation. Single Look Complex (SLC) SAR images were produced using the SARPROZ software [18]. We use the $90 \mathrm{~m}$ resolution SRTM [19] digital elevation model, resampled to $3 \mathrm{~m}$ using bi-cubic interpolation, to calculate and remove topographic residuals and for geocoding. We co-registered a set of 62 images spanning from December 2012 to July 2015 from an ascending geometry (satellite moving from South to North and looking towards East) with a right-looking radar direction and a ground incidence angle of 35.5 degrees. The data have been acquired with a regular frequency of 16 days from December 2012 through September 2013, using only the second satellite (CSK2) while the full constellation of four satellites acquired data during the period from September 2013 to July 2014 with 4 irregularly spaced acquisitions over 16 days. This allowed us to better constrain the transient deformation that occurred during this time interval. Figure 2B shows the cumulative deformation map localizing the dissolution process on the east side of the dam while figure $2 \mathrm{C}$ shows the CSK time-series highlighting the dynamic behavior of the deformation and the increase in the dissolution rate after the dam maintenance stopped.
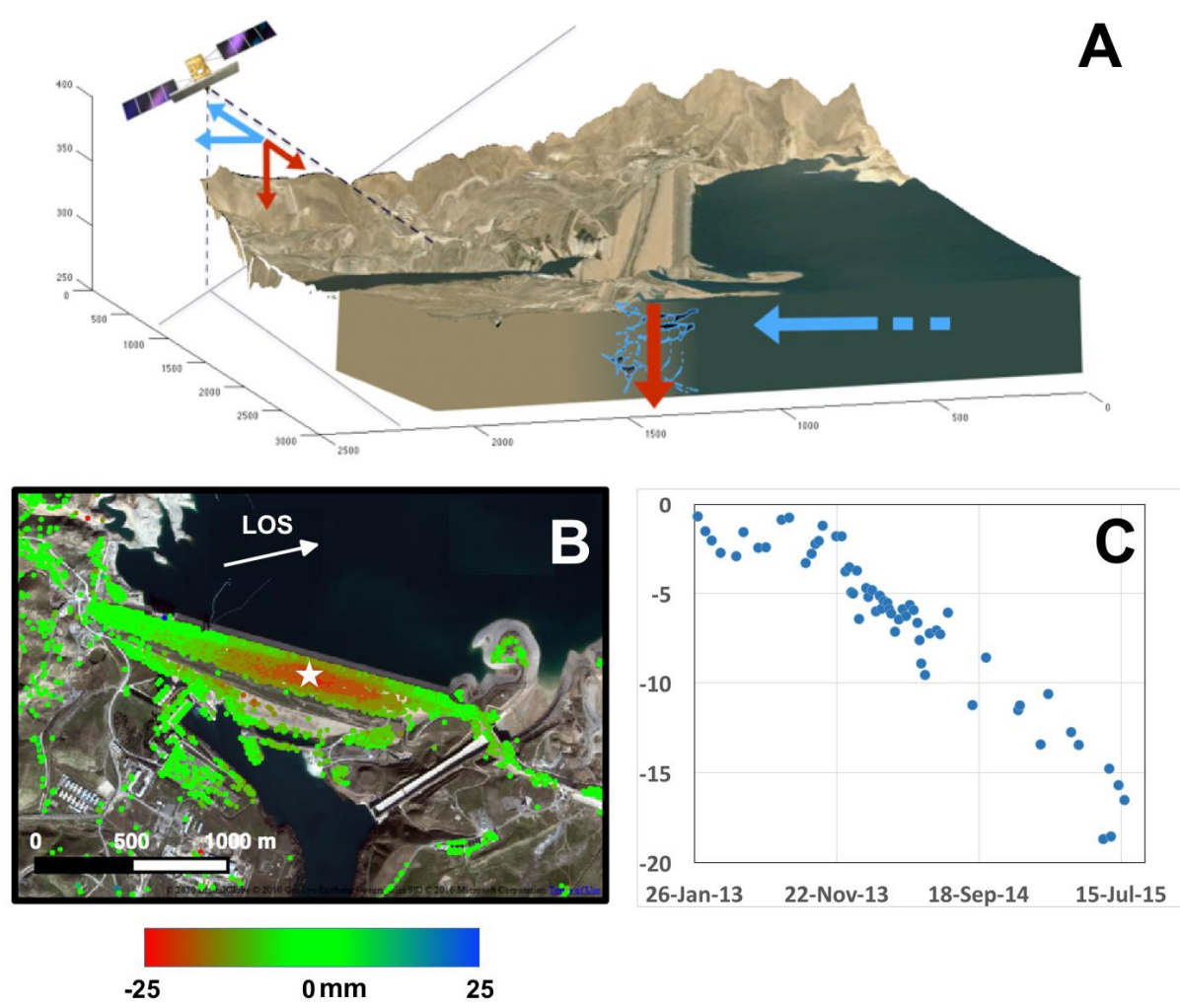

Figure 2 (A) Schematic description of the different forces acting on the Mosul dam wall re-projected along the CSK line of sight. Vertical subsidence translates in motion away from the sensor while increased pressure at the dam walls result in motion toward the SAR sensors. In this particular case the heading angle makes the CSK data insensitive to the hydrological induced signal. (B) Cumulative deformation map over the Mosul dam covering December 2012 - July 2015. (C) Time series showing the dynamic of deformation at the starred point in (B). 


\section{ARCHEOLOGICAL AND CULTURAL HERITAGE SITES}

There is already a plethora of studies demonstrating that space-borne SAR can be effectively used for monitoring archeology and cultural heritage. One of the earliest uses was archaeological prospection by exploiting the SAR penetration capabilities and dates back to the 1980's when [20] identified ancient structures hidden beneath the canopy and agricultural signatures trying to reconstruct ancient Maya population land use using SEASAT data. Many more studies followed [21-25] making SAR a powerful means of site discovery. As time series analysis techniques developed $[13,14]$, there has been a growing interest in InSAR and its potential to enable advances in archeology and cultural heritage areas monitoring. Several examples in literature show a SAR based structural health monitoring system successfully applied to cultural heritage areas and monuments [26-29]. These advancements in the techniques are increasingly used by archeologists [30] and have become of interest for structural engineers interested in surveying archeological sites and cultural heritage areas [31].

In the following paragraph we show two examples. The first one relates to a SAR based structural health monitoring system applied to the Tramontano medieval castle in Matera to assess the effectiveness of the restoration works. The second shows the changes in the archeological area of Palmyra in Syria, where the Syrian army prepared the battlefield modifying archeological sites and surrounding areas.

\subsection{The Tramontano castle, Matera (Italy)}

The Tramontano castle (Lat. $40.663^{\circ} \mathrm{N}$, Lon. $16.606^{\circ} \mathrm{E}$ ) is located on the Lapillo hill next to the ancient town of Matera, Basilicata (Italy). It was build starting in 1501 by the Count Giovan Carlo Tramontano and it was never finished. As observed in several other medieval sites of this region [32,33], the castle is characterized by evident collapses due to landslides, cracks, structural discontinuities, unstable rock blocks, accumulate debris and discontinuity crests signs of ongoing morphogenetic dynamics [34]. Analysis of the Italian Landslide Inventory (IFFI) revealed the presence of a dormant, relatively shallow landslide affecting the area of the castle and north-eastern slope of the Lapillo hill [40].

Restoration works to preserve the castle and the surrounding area started in 2008 and are still ongoing. We processed 121 COSMO-SkyMed StripMap images covering the period 2008-2015 acquired from both ascending (56 images Fig. $3 \mathrm{~A}$ ) and descending (65 images Fig. 3B) geometries to monitor the stability of the Tramontano castle. By interpreting both the SAR time-series we found that since November 2012 the area is mainly characterized by a downhill horizontal movement (Fig 3C-3D) affecting the southern side of the castle. We performed ground measurements to validate the deformation estimates and found $\sim 2 \mathrm{~cm}$ opening cracks in the southern side and the southern tower (Fig 3E-H). This partially confirms the MT-InSAR results. The ground measurements were then used as an input to analyze in more detail the location of the scatters observed in the SAR data. By looking at the SAR ascending and descending mean amplitudes it is apparent that different geometries observe different targets located on the front façade and the backward side of the tower, respectively (Fig3E and 3G). In particular, the difference between the observed cracks and MT-InSAR results arise when looking at the the descending time series (Fig. 3D) where a linear trend is evident starting 2008 and accounts for a total cumulative displacement of $\sim 4 \mathrm{~cm}$ while the ground measurements evidenced $\sim 2 \mathrm{~cm}$ cracks affecting the south tower. This discrepancy between InSAR and ground measurements can be explained by taking into account the ongoing restoration works which covered the evidence of previously existing cracks. In this case the complementarity of the InSAR time-series and the ground measurements was fundamental to confirm the deformation trends, locate precisely the scatter imaged by the SAR sensor and assess the effectivity of the restoration works. As found in earlier InSAR studies of building damage assessment [35,36], this iterative approach is recommended to find a match between the ground truth and the satellite evidence, in order to assess in a more quantitative way the accuracy of the deformation estimates along the satellite LOS. Given that the area is characterized by soluble bedrock, further research might use ancillary data such as rain records to investigate the role of groundwater levels to trigger dissolution and cause structural destabilization of the castle.

Proc. of SPIE Vol. 10003 100030N-6 

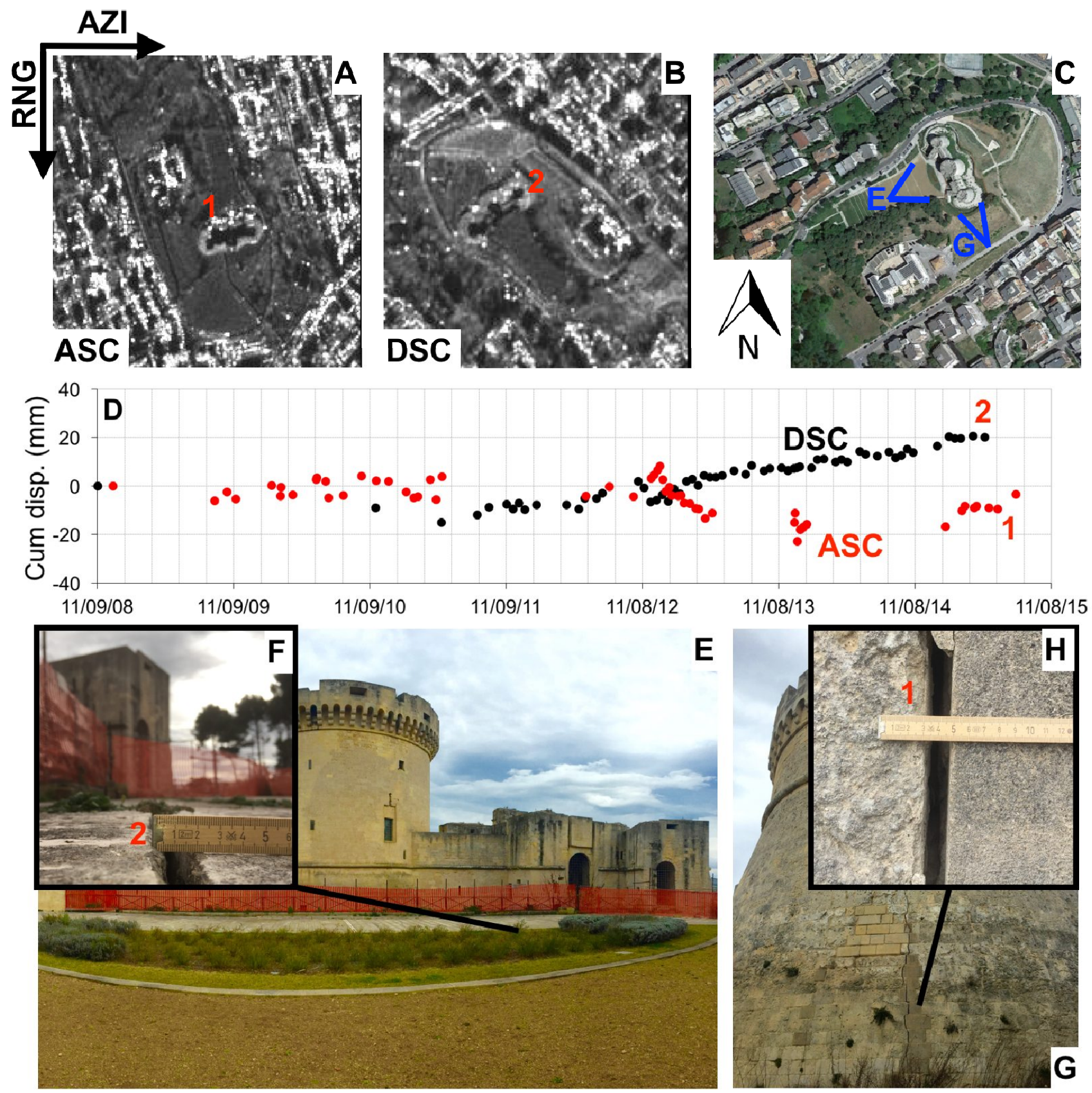

Figure 3 (A) Ascending and (B) descending mean amplitude images of the Tramontano castle, Matera. The numbers 1) and 2) represent the scatterers the cumulative displacement time series of which are showed in figure 3D. The images are in radar coordinates to preserve the initial resolution and make the scatterers identification easier. (C) Google earth optical view of the castle. Blue triangles represent the perspective of the photographs showed in (E) and (G).(D) Cumulative deformation time-series from ascending and descending CSK data (E) View of the west façade of the castle, with a zoom in inset (F) showing $\sim 2 \mathrm{~cm}$ crack found in the stone block pavement along the west façade. (G) South tower of the castle showing evident cracks. Adjacent cracks have been covered in previous restoration works. (H) Zoom view of the crack running vertically with $\sim 2 \mathrm{~cm}$ of opening.

\subsection{The Palmyra archeological site, Syria}

Located in the middle of the Syrian desert, the ancient city of Palmyra (Lat. $34.568^{\circ} \mathrm{N}$, Lon. $38.290^{\circ} \mathrm{E}$ ) is one of the most important archeological sites in Syria. Inscribed in the UNESCO World heritage list since 1980, Palmyra has been threatened since 2012 when military units of the Syrian army were deployed in the nearby city of Tadmor [37] to protect 
the area from ISIL. According to the report of the association for the protection of Syrian archaeology during this period the Syrian army made several changes within the archeological site including removal of soil, digging trenches and building roads. One of these roads was built in the archeological site of Palmyra in order to directly connect the police station with the center of military operations close to the telecommunications tower on Gabal al-Rwissat (Fig 4C)[37]. This $10 \mathrm{~m}$ wide road is protected by lateral levees and caused partial damage to the Diocletian rampart and led to the removal of some funerary towers foundations. A 2 meter-high leave of earthen dyke has been erected as protection of the police station in the west-east direction, parallel to the main road.

A SAR qualitative analysis comparing pre- and post-event amplitude images reveals these changes occurred in 2 years. We generated an RGB map using two CSK stripmap images acquired on November 13th 2011 (red channel) and December $7^{\text {th }} 2013$ (green and blue channesl) (Fig. 4). The main source of noise is speckle and soil moisture variation which affect the calibrated SAR amplitudes and introduce false alarms in the visual classification.

The RGB map shows blue features for targets increasing backscattered signal in 2013 while red pixels highlight targets that lowered their radar cross section loosing visibility to the SAR antenna. The main blue features can be attributed to the creation of scatterers such as levees (Fig 4A -B) while the red areas can be classified as roads as in the case of the road created close to the Sanctuary of Bel (Fig 4A), removed barriers (Fig 4D) and likely destroyed structures nearby the airport (Fig 4D). As proved in recent research in other Syrian sites [30,39], although not quantitative and characterized by a performance that might be constrained by visibility to the LOS satellite, this change detection method is quite effective to highlight new structures and features that are due to operations during armed conflicts and can act as a knowledge gap filler with regard to optical satellite imagery (e.g. those available via freely access commercial imagery tools like Google Earth). 


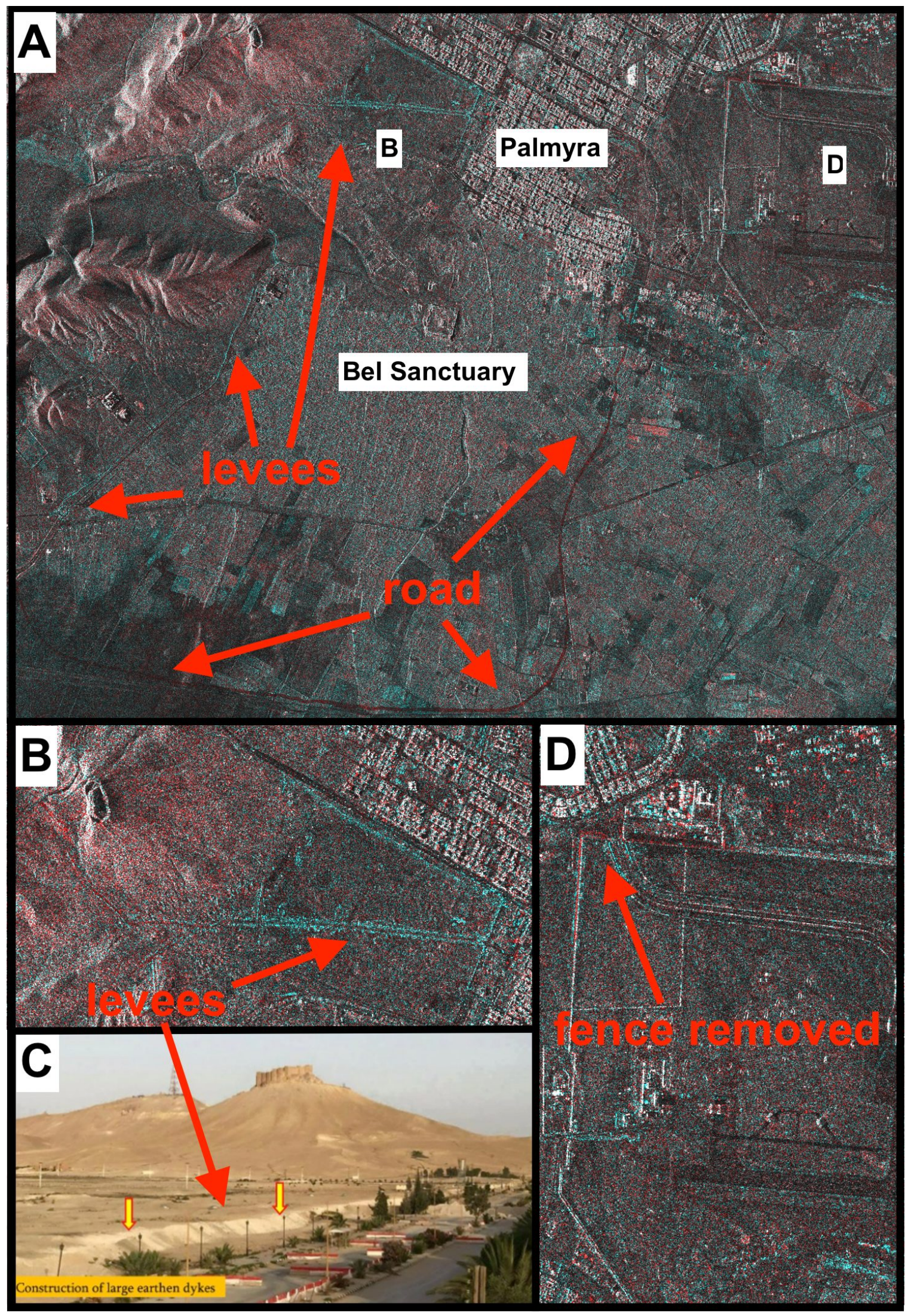

Figure 4 (A) RGB map of the Bel sanctuary in Palmyra, Syria, showing a supplementary road (red) and dykes built for defense purposes against ISIL by the Syrian army; (B) Palmyra archeological site, the blue lines highlight the dykes protecting the police station and the road connecting the city with the battlefield. (C) Google earth optical view (modified from [37]) dykes close to the police station. (D) Inset of the Palmyra airport showing that parts of the fence have been removed. 


\section{CONCLUSIONS}

We presented results from COSMO-SkyMed (CSK) and TerraSAR-X SAR observations applied to the remote sensing of engineered structures and archeological sites. We used multiple-geometry SAR-based products exploiting both phase and amplitude of the SAR signal addressing the main objectives of an SHM system including detection and localization. We monitored two different processes related to dams engineering concerning seasonal induced deformation and destabilization linked to dissolution of local evaporites underlying the Mosul dam foundation. We performed a stability analysis of the Tramontano castle (Matera, Italy) monitoring the restoration work status in the period 2008-2015 and performed a qualitative analysis of the archeological area of Palmyra in 2011-2013 to identify changes made by the Syrian army while preparing the battlefield for the incoming ISIL offensive. In these examples we highlighted how low latency data access combined with short-interval imaging is enhancing the ability to track anthropogenic changes on the Earth's surface making a SAR SHM system a fundamental tool for hazard assessment and response.

\section{ACKNOWLEDGEMENTS}

We thank the Italian Space Agency (ASI) for providing COSMO-SkyMed data for this project. Original COSMOSkyMed product ASI Agenzia Spaziale Italiana (2014-2016). Part of the COSMO-SkyMed data data were provided under proposal AO-178. We thank the German Aerospace Centre (DLR) for providing TerraSAR-X data for this project. TerraSAR-X data were provided under proposal LAN2959. All the reservoir data (from 2010 to June 2015) for the Pertusillo dam have been provided by the Ente per lo Sviluppo dell'Irrigazione e la Trasformazione Fondiaria agency of Potenza, Italy. The seismic data were accessed from the Istituto Nazionale di Geofisica e Vulcanologia (INGV) ISIDE database http://iside.rm. ingv.it/http://iside.rm.ingv.it/ (data available since 7 July 2015; last accessed July 2015). The work of P. Milillo was done while he was a visiting student researcher at Caltech and partially sponsored by the National Aeronautics and Space Administration Postdoctoral Program.

\section{REFERENCES}

[1] Farrar, C. R., Doebling, S. W., \& Nix, D. A., "Vibration-based structural damage identification," Philosophical Transactions of the Royal Society of London A Mathematical Physical and Engineering Sciences 359(1778), 131149 (2001).

[2] Cigna, F., Lasaponara, R., Masini, N., Milillo, P., Tapete, D., "Persistent scatterer interferometry processing of COSMO-SkyMed StripMap HIMAGE time series to depict deformation of the historic centre of Rome, Italy," Remote Sensing, 6(12), 12593-12618 (2014).

[3] Milillo, P., Perissin, D., Salzer, J. T., Lundgren, P., Lacava, G., Milillo, G., Serio, C., "Monitoring dam structural health from space: Insights from novel InSAR techniques and multi-parametric modeling applied to the Pertusillo dam Basilicata, Italy," International Journal of Applied Earth Observation and Geoinformation 52, 221-229 (2016).

[4] Rocca, F., Prati, C., Guarnieri, A. M., Ferretti, A., "SAR interferometry and its applications," Surveys in Geophysics 21(2-3), 159-176 (2000).

[5] Yun, S. H., Hudnut, K., Owen, S., Webb, F., Simons, M., Sacco, P., Gurrola E., Manipon G., Liang C., Fielding E., Milillo, P., "Rapid Damage Mapping for the 2015 Mw 7.8 Gorkha Earthquake Using Synthetic Aperture Radar Data from COSMO-SkyMed and ALOS-2 Satellites,” Seismological Research Letters 86(6), 1549-1556 (2015). 
[6] Fielding, E. J., Simons, M., Owen, S., Lundgren, P., Hua, H., Agram, P., Liu, Z., Moore A., Milillo, P., Polet, J., ... Samsonov, S., Rosen, P., Webb, F., Milillo, G., "Rapid imaging of earthquake ruptures with combined geodetic and seismic analysis," Procedia Technology 16, 876-885 (2014).

[7] Barnhart, W. D., Murray, J. R., Yun, S. H., Svarc, J. L., Samsonov, S. V., Fielding, E. J., Brooks, B., A., Milillo, P., "Geodetic constraints on the 2014 M 6.0 South Napa earthquake," Seismological Research Letters 86(2A), 335-343 (2015).

[8] Lundgren, P., Kiryukhin, A., Milillo, P., \& Samsonov, S., "Dike model for the 2012-2013 Tolbachik eruption constrained by satellite radar interferometry observations," Journal of Volcanology and Geothermal Research 307, 79-88 (2015).

[9] Milillo, P., Fielding, E. J., Shulz, W. H., Delbridge, B., \& Burgmann, R., "COSMO-SkyMed spotlight interferometry over rural areas: The Slumgullion landslide in Colorado, USA," IEEE Journal of Selected Topics in Applied Earth Observations and Remote Sensing 7(7), 2919-2926 (2014).

[10] Rousset, B., Jolivet, R., Simons, M., Lasserre, C., Riel, B., Milillo, P., Cakir, Z., Renard, F. "An aseismic slip transient on the North Anatolian Fault," Geophysical Research Letters 43(7), 3254-3262 (2016).

[11] Riel, B., Milillo, P., Simons, M., Lundgren, P., Kanamori, H., Samsonov, S., "The collapse of Bárðarbunga caldera, Iceland," Geophysical Journal International 202(1), 446-453 (2015).

[12] Milillo, P., Riel, B., Minchew, B., Yun, S. H., Simons, M., Lundgren, P., "On the Synergistic Use of SAR Constellations' Data Exploitation for Earth Science and Natural Hazard Response," IEEE Journal of Selected Topics in Applied Earth Observations and Remote Sensing 9(3), 1095-1100 (2016).

[13]Ferretti, A., Prati, C., Rocca, F., "Nonlinear subsidence rate estimation using permanent scatterers in differential SAR interferometry," IEEE Trans. Geosci. Remote Sens. 38 (5), 2202-2212 (2000).

[14]Ferretti, A., Prati, C., Rocca, F., "Permanent scatterers in SAR interferometry. IEEE Trans. Geosci. Remote Sens. 39 (1), 8-20 (2001).

[15] Perissin, D., Prati, C., "Identifying urban SAR permanent scatterers for motion interpretation and multi-track data fusion." Riv. ital. Telerilevamento 40 (2), 115-121 (2008).

[16]Perissin, D., Prati, C., Rocca, F., "ASAR parallel-track PS analysis in urban sites," Proc. IGARSS 1167-1170 (2007)

[17] Bowen, S.W., "Office of the special Inspector General for Iraq Reconstruction. Relief and reconstruction funded work at Mosul dam Mosul, Iraq. , (2007) (date of access: 16/03/2016)". (http://cybercemetery.unt.edu/archive/sigir/20131001121159/http:/www.sigir.mil/files /assessments/PA-07-105.pdf)

[18] Perissin, D., Wang, Z., \& Wang, T., "The SARPROZ InSAR tool for urban subsidence/manmade structure stability monitoring in China," Proc. ISRSE 1015, (2011).

[19]Farr, T. G., Kobrick, M., "Shuttle Radar Topography Mission produces a wealth of data," Eos Transactions American Geophysical Union 81(48), 583-58 (2000).

[20] Adams, R. E., Brown Jr, W. E., \& Culbert, T. P., "Radar mapping, archaeology, and ancient Maya land use," Science 213(4515), 1457-1463 (1981).

[21] McCauley F., G.G. Schaber, C.S. Breed, M.J. Grolier, C.V. Haynes, B. Issawi, C. Elachi, R. Blom, "Subsurface valleys and geoarchaeology of the eastern Sahara revealed by shuttle radar, Science 218, 1004-1020 (1982)

[22]Blom, R., \& Hedges, G. R., "Space technology and the discovery of the lost city of Ubar," Proc. Aerospace Conference 1997 IEEE, Vol. 1, pp. 19-28 (1997).

[23] Clark, C. D., Garrod, S. M., \& Pearson, M. P., "Landscape archaeology and remote sensing in southern Madagascar," International Journal of Remote Sensing 19(8), 1461-1477 (1998).

[24] Blom, R. G., Crippen, R. E., Zarins, J., \& Hedges, G. R., "Remote sensing, shuttle radar topographic mapper data, and ancient frankincense trade routes,"Proc. IGARSS, Vol. 6, pp. 2477-2479. (2000).

[25]Blom, R. G., Chapman, B., Podest, E., \& Murowchick, R., "Applications of remote sensing to archaeological studies of early Shang civilization in northern China," Proc. IGARSS, Vol. 6, pp. 2483-2485 (2000).

[26] Tapete, D., Fanti, R., Cecchi, R., Petrangeli, P., \& Casagli, N., "Satellite radar interferometry for monitoring and early-stage warning of structural instability in archaeological sites," Journal of Geophysics and Engineering 9(4), S10 (2012).

[27] Tapete, D., \& Cigna, F., "Rapid mapping and deformation analysis over cultural heritage and rural sites based on Persistent Scatterer Interferometry,” International Journal of Geophysics, (2012).

[28] Tapete, D., Casagli, N., \& Fanti, R., "Radar interferometry for early stage warning on monuments at risk," Landslide Science and Practice, pp. 619-625 (2013). 
[29] Gigli, G., Frodella, W., Mugnai, F., Tapete, D., Cigna, F., Fanti, R., ... \& Lombardi, L., "Instability mechanisms affecting cultural heritage sites in the Maltese Archipelago," Natural hazards and earth system sciences 12(6), 18831903 (2012).

[30] Tapete, D., Cigna, F., "Trends and perspectives of space-borne SAR remote sensing for archaeological landscape and cultural heritage applications," Journal of Archaeological Science: Reports, (2016).

[31] Chen, F., Masini, N., Yang, R., Milillo, P., Feng, D., \& Lasaponara, R., "A space view of radar archaeological marks: First applications of COSMO-SkyMed X-band data," Remote Sensing 7(1), 24-50 (2014).

[32] Sdao, F., Pascale, S., and Rutigliano, P., "Instabilita' dei versanti e controllo, mediante tecniche integrate di monitoraggio delle frane presenti in due siti sacri del Parco Archeologico Storico Naturale delle Chiese Rupestri di Matera," SIRIS Studi e ricerche della Scuola di Specializzazione in Archeologia di Matera 9 (2008), 87-100, 2009.

[33] Cotecchia, V. and Grassi, D., "Incidenze geologico-ambientali sull'ubicazione e lo stato di degrado degli insediamenti rupestri medioevali della Puglia e della Basilicata," Geol. Appl. e Idrogeol 32, 1-10, 1997.

[34] Sdao, F., Lioi, D. S., Pascale, S., Caniani, D., \& Mancini, I. M., "Landslide susceptibility assessment by using a neuro-fuzzy model: a case study in the Rupestrian heritage rich area of Matera," Natural Hazards and Earth System Sciences 13(2), 395-407 (2013).

[35] Cigna, F., Del Ventisette, C., Liguori, V., and Casagli, N., "Advanced radar-interpretation of InSAR time series for mapping and characterization of geological processes," Natural Hazards and Earth System Sciences 11, 865-881 (2011).

[36] Bianchini, S., Tapete, D., Ciampalini, A., Di Traglia, F., Del Ventisette, C., Moretti, S., Casagli, N., "Multitemporal evaluation of landslide-induced movements and damage assessment in San Fratello (Italy) by means of Cand X-band PSI data," Mathematics of Planet Earth Lecture Notes in Earth System Sciences, (pp. 257-261)

[37] Cheikhmous A., Palmyra Heritage Adrift. Detailed report on all damage done to the archaeological site between February. 2012 and June 2015. The Association for the Protection of Syrian Archaeology, last date accessed August 16th 2016 http://www.asor-syrianheritage.org/wp-content/uploads/2015/06/Palmyra_Heritage_Adrift.pdf (2016).

[38] Tapete, D., Cigna, F., Donoghue, D.N.M., Philip G., "Mapping changes and damages in areas of conflict: from archive C-band SAR data to new HR X-band imagery, towards the Sentinels," Proc. Fringes, (2015)

[39] Tapete, D., Cigna, F., "Urban remote sensing in areas of conflict: TerraSAR-X and Sentinel-1 change detection in the Middle East" Proc. SPIE 9688

[40]ISPRA Inventario dei Fenomeni Franosi in Italia last date accessed August 22nd 2016 http://193.206.192.136/cartanetiffi/ 